\title{
Síntese e Sulfonação de Resinas Poliméricas Macroporosas e Avaliação na Remoção de Petróleo e de Anilina em Água
}

\author{
Thiago Muza Aversa, Yure Gomes de Carvalho Queirós, Elizabete Fernandes Lucas \\ Instituto de Macromoléculas Professora Eloísa Mano, UFRJ \\ Ana Maria Travalloni Louvisse \\ Centro de Pesquisas Leopoldo Américo Miguez de Mello (CENPES), Petrobras
}

\begin{abstract}
Resumo: Resinas poliméricas porosas têm sido amplamente empregadas nos processos de tratamento de água devido a vantagens como elevada seletividade e possibilidade de regeneração e modificação química, permitindo a obtenção de um material com maior seletividade/especificidade. No presente estudo, resinas poliméricas porosas de metacrilato de metila-divinilbenzeno (MMA-DVB), estireno-divinilbenzeno (Sty-DVB) e estireno-divinilbenzeno sulfonada (S-StyDVB) foram sintetizadas, caracterizadas e avaliadas quanto à eficiência de remoção de petróleo e de anilina contidos na água. Nos testes empregando-se água oleosa, foram avaliadas colunas contendo somente um tipo de resina (StyDVB e S-Sty-DVB) e colunas contendo recheios mistos (MMA-DVB/S-Sty-DVB e Sty-DVB/S-Sty-DVB), frente à remoção de óleo e dos cátions sódio e cálcio presentes na água oleosa. As colunas com recheio misto apresentaram melhor desempenho, devido à diversidade de hidrofilicidade do sistema adsorvente, tendo sido possível remover uma gama mais extensa de contaminantes. A remoção de anilina presente na água foi possível com o uso da resina de estireno-divinilbenzeno sulfonada, em razão da reação ácido-base entre a anilina e os sítios ácidos da resina. Uma redução gradual, e não abrupta, da eficiência desta resina na remoção de anilina deve-se à interação de moléculas de anilina com o sal de anilínio formado após a saturação dos sitos ácidos da resina.
\end{abstract}

Palavras-chave: Resinas poliméricas, sulfonação, água oleosa produzida, TOG, anilina, tratamento de água.

\section{Synthesis and Sulfonation of Macroporous Polymeric Resins and their Assessment for Removal of Oil and Aniline from Water}

\begin{abstract}
Polymeric resins have been widely used in water treatment processes due to their advantages, such as high selectivity and possibility of regeneration and chemical modification, allowing obtaining a material with greater selectivity/specificity. In the present study, porous polymeric resins of methyl methacrylate-divinylbenzene (MMADVB), styrene-divinylbenzene (Sty-DVB) and sulfonated styrene-divinylbenzene (S-Sty-DVB) were synthesized, characterized and evaluated for their efficiency in removing oil and aniline contained in water. In the tests with oily water, the efficiency in removing oil and cations of sodium and calcium was assessed with columns containing only one type of resin (Sty-DVB or S-Sty-DVB) and columns containing blended filling (MMA-DVB/S-Sty-DVB and Sty-DVB/S-Sty-DVB). The columns containing the mixture performed better, due to the diverse hydrophilicity of the adsorbent system, allowing removal of a wider range of contaminants. The removal of aniline from the water was possible with the use of the sulfonated styrene-divinylbenzene because of the reaction between the aniline and acidic sites of the resin. The efficiency of this resin in removing aniline declined gradually rather than abruptly, due to the interaction of the aniline molecules with the aniline salt formed after saturation of the resin's acidic sites.
\end{abstract}

Keywords: Polymeric resins, sulfonation, produced oily water, TOG, aniline, water treatment.

\section{Introdução}

A água oleosa produzida é um tipo de água oriunda do processo de produção do petróleo, gerada concomitantemente com o óleo e o gás natural, podendo atingir níveis de mais de $95 \%$ dependendo da maturação do poço em questão. Essa água contém inúmeros contaminantes inorgânicos, como sais e metais pesados, e orgânicos, muitos destes extremamente tóxicos ao meio ambiente, como por exemplo, hidrocarbonetos aromáticos da classe dos BTEX (benzeno, tolueno, etilbenzeno e xilenos), hidrocarbonetos poliaromáticos, ácidos orgânicos e compostos sulfurados, oxigenados e nitrogenados ${ }^{[1-4]}$

Em razão da elevada toxidez dos contaminantes é necessário tratar a água visando removê-los ou reduzir seus índices até que atinjam os limites estabelecidos pelas legislações locais. No Brasil, estes limites são estabelecidos pela resolução CONAMA n ${ }^{\circ} 393$ de 8 de agosto de 2007, a qual estabelece níveis de teor total de óleos e graxas (TOG) mensais de $29 \mathrm{mg} / \mathrm{L}$, podendo atingir picos diários de $42 \mathrm{mg} / \mathrm{L}^{[5]}$. 
Diversas técnicas de tratamento têm sido utilizadas para a redução de TOG da água como, por exemplo, extração por solvente ${ }^{[6]}$ e separação por membrana ${ }^{[7-9]}$. No entanto, a possibilidade de emprego de resinas poliméricas porosas no tratamento da água produzida vem se intensificando em virtude de suas vantagens, como baixo custo, possibilidade de regeneração e reutilização, elevada seletividade e possibilidade de realização de modificações químicas por meio de reações tais como as realizadas para moléculas de baixa massa molar ${ }^{[10-13]}$.

Dentre essas reações químicas, a sulfonação consiste de uma importante forma de modificação tendo seu uso no tratamento de água, principalmente nos processos de deionização e "amolecimento" de água dura, pela remoção de cátions cálcio e magnésio ${ }^{[14-15]}$. Outra aplicação para as resinas sulfonadas refere-se à sua utilização como suporte catalítico ${ }^{[16-19]}$. Na literatura, no entanto, não foi encontrado um estudo detalhado da utilização de resinas sulfonadas no tratamento da água oleosa.

Este trabalho apresenta a avaliação do desempenho de três resinas poliméricas (metacrilato de metiladivinilbenzeno, estireno-divinilbenzeno e estirenodivinilbenzeno sulfonada) no tratamento de dois sistemas aquosos contaminados: um com petróleo e outro com anilina. A anilina foi selecionada como molécula modelo representando os compostos aromáticos polares do petróleo. Foram empregadas colunas com recheio misto de modo a minimizar a interferência causada pelo óleo no fenômeno da troca iônica. As resinas foram obtidas via polimerização em suspensão e os ensaios de desempenho foram conduzidos em leito fixo.

\section{Materiais e Métodos}

\section{Síntese dos copolímeros por polimerização em suspensão}

Uma pré-polimerização foi conduzida com os monômeros e o iniciador peróxido de benzoíla (1\% em mol de monômeros) à $50^{\circ} \mathrm{C}$ durante 30 minutos sob agitação magnética e atmosfera inerte (fluxo de nitrogênio). As razões entre os monômeros são mostradas na Tabela 1.

Em seguida, foi adicionado heptano (diluente não solvatante) em volume igual ao da mistura de monômeros. Separadamente, foi preparada a fase aquosa composta por água, gelatina ( $1 \%$ em massa da fase aquosa) e $\mathrm{NaCl}(2 \%$ em massa da fase aquosa).

A duas fases foram misturadas, a uma razão fase aquosa/fase orgânica de 3:1 com agitação mecânica à temperatura de $80^{\circ} \mathrm{C}$ por 24 horas em atmosfera inerte de nitrogênio, sendo o material obtido lavado três vezes

Tabela 1. Denominação dos polímeros obtidos e razões de monômeros utilizadas na alimentação.

\begin{tabular}{ccc}
\hline Polímero & Monômeros & Razão (mol) \\
\hline MMA-DVB & MMA e DVB & $5: 1$ \\
Sty-DVB & Sty e DVB & $5: 1$ \\
\hline
\end{tabular}

MMA-DVB = Copolímero de metacrilato de metila (MMA) e divinilbenzeno (DVB) Sty-DVB = Copolímero de estireno (Sty) e divinilbenzeno (DVB). com água quente, três vezes com etanol e mais uma vez com água quente. Após as lavagens, o material foi filtrado e seco em estufa com circulação de ar à $60^{\circ} \mathrm{C}$ durante 24 horas.

\section{Sulfonação do copolímero SDVB}

Sobre a resina seca foi vertido ácido sulfúrico concentrado na proporção de $1 \mathrm{~g}$ resina $/ 5 \mathrm{~mL}$ de ácido ${ }^{[20]}$. $\mathrm{O}$ sistema mantido à $100^{\circ} \mathrm{C}$ sob agitação magnética branda e refluxo por 2 horas. Ao final da reação, o conteúdo do balão foi sucessivamente diluído com água destilada, filtrado sob vácuo, lavado com metanol e seco em estufa com circulação de ar à $60^{\circ} \mathrm{C}$ por 24 horas.

\section{Caracterização das resinas}

As resinas MMA-DVB e Sty-DVB foram caracterizadas quanto à densidade aparente, inchamento percentual volumétrico, microscopia óptica, porosidade (área superficial e volume de poros) e espectroscopia na região do infravermelho. Além dessas técnicas, o copolímero sulfonado (S-Sty-DVB) também foi caracterizado quanto à capacidade de troca catiônica.

Para o cálculo da densidade aparente (d), determinado volume de resina seca foi acondicionado em proveta previamente tarada. Este sistema foi pesado e os dados foram utilizados na Equação 1.

$$
\mathrm{d}=\mathrm{m}(\mathrm{g}) / \mathrm{V}(\mathrm{mL})
$$

Para o cálculo do inchamento percentual volumétrico (I), volume suficiente de solvente foi adicionado a determinado volume $\left(\mathrm{V}_{\mathrm{i}}\right)$ de resina seca acondicionada em proveta. Após 24 horas, foi observado o volume ocupado pela resina $\left(\mathrm{V}_{\mathrm{f}}\right)$. Os volumes observados foram utilizados na Equação 2.

$$
\mathrm{I}=\left[\left(\mathrm{V}_{\mathrm{f}}-\mathrm{V}_{\mathrm{i}}\right) / \mathrm{V}_{\mathrm{i}}\right] \times 100
$$

As análises por microscopia óptica foram realizadas com o microscópio óptico Olimpus SZH 10 research Stereo e câmera fotográfica Nikon Coolpix 5400, utilizando as resinas secas, a fim de se observar suas características morfológicas, como esfericidade e porosidade, esta última relacionada ao aspecto leitoso do material.

As porosidades foram determinadas em um equipamento ASAP 2020 Micromeritics. As amostras foram pré-tratadas através de secagem à temperatura $150^{\circ} \mathrm{C}$, a uma taxa de $10^{\circ} \mathrm{C} / \mathrm{min}$, durante 4 horas, seguida de uma posterior secagem sob vácuo $(4 \mu \mathrm{m}$ de $\mathrm{Hg})$ a $150^{\circ} \mathrm{C}$ por 2 horas.

Os espectros de absorção na região do infravermelho médio (4000-400 $\mathrm{cm}^{-1}$ ) foram obtidos em espectrômetro Varian 3100 FTIR. As resinas foram utilizadas secas, com o emprego do acessório ATR/diamante.

Para os cálculos da capacidade de troca catiônica, primeiramente, foi determinado o teor de sólidos totais usando a Equação 3, onde determinada massa de resina sulfonada foi levada à estufa com circulação de ar à $110^{\circ} \mathrm{C}$ por 12 horas até peso constante.

$$
\% \text { sólidos totais }=\left(\mathrm{m}_{\text {seca }} / \mathrm{m}_{\text {úmida }}\right) \times 100
$$


A capacidade de troca catiônica foi determinada através de volumetria utilizando solução padrão de hidróxido de sódio $(0,1 \mathrm{M})$ e ácido clorídrico $(0,1 \mathrm{M}) .1$ $\mathrm{g}$ de resina em sua forma ácida foi deixada em contato com $50 \mathrm{~mL}$ da solução padrão de hidróxido de sódio $(0,1 \mathrm{M})$ durante 12 horas. Após esse período, $10 \mathrm{~mL}$ do sobrenadante foram titulados com solução padrão de ácido clorídrico $(0,1 \mathrm{M})$, utilizando fenolftaleína como indicador. A Equação 4 foi utilizada para o cálculo da capacidade de troca catiônica (CEC) da resina.

$\mathrm{CTC}=\left[\left(50 \mathrm{~mL} \times \mathrm{M}_{\mathrm{NaOH}}\right)-5 \mathrm{x}\right.$

$\left.\left(\mathrm{V}_{\text {HClgasto }} \times \mathrm{M}_{\mathrm{HCl}}\right)\right] /\left[\mathrm{m}_{\text {amostra }}(\%\right.$ sólidos totais / 100)]

\section{Preparo de água contaminada com anilina e determinação dos teores de anilina}

A água contaminada com anilina foi preparada solubilizando-se $100 \mu \mathrm{L}$ de anilina em $1 \mathrm{~L}$ de água destilada. A quantificação da anilina na água, antes e após o tratamento foi realizada com extração prévia com hexano, à razão de 1:1, sendo então a fase orgânica analisada por cromatografia gasosa de alta resolução (cromatógrafo Shimadzu GC-17A - Coluna DB-5, 25 m de comprimento, 0,25 mm de diâmetro) nas seguintes condições: (i) temperaturas do forno: inicial: $40^{\circ} \mathrm{C}$ (por 3 minutos); final: $290^{\circ} \mathrm{C}$ (por 5 minutos); (ii) taxa de aquecimento: $20^{\circ} \mathrm{C} /$ minuto; (iii) temperatura do injetor: $250^{\circ} \mathrm{C}$; (iv) temperatura do detector: $325^{\circ} \mathrm{C}$; (v) modo de injeção: split 1:1 (com divisão de fluxo).

Previamente às análises foi construída uma curva de calibração com soluções de anilina em hexano em diferentes concentrações.

\section{Preparo de água contaminada com óleo e determinação dos teores de óleos e graxas}

O preparo e a dosagem da água oleosa sintética foram realizados como descrito na literatura ${ }^{[4]}$, sendo a concentração teórica de óleo na água igual a 200 ppm.

\section{Eluição da água contaminada}

O processo de eluição seguiu aquele descrito na literatura ${ }^{[4]}$, sendo que a coluna de aço utilizada possuía $7,38 \mathrm{~mm}$ de diâmetro $\times 30,18 \mathrm{~mm}$ de altura, o que corresponde a cerca de $1 \mathrm{~mL}$ de volume de leito. As vazões empregadas foram de $7 \mathrm{~mL} / \mathrm{min}$ para a água com óleo e $2 \mathrm{~mL} / \mathrm{min}$ para água com anilina, o que corresponde aos tempos de residência da água contaminada no interior da coluna de $8,5 \mathrm{~s}$ e $30 \mathrm{~s}$, respectivamente.
No total, foram preparadas seis colunas, sendo que quatro foram avaliadas quanto à remoção de óleo e duas foram avaliadas quanto à remoção de anilina. A Tabela 2 resume os tipos de recheios de coluna utilizados em cada caso. Nas colunas de recheio misto as resinas foram dispostas em série, de modo que a água contaminada entrasse em contato primeiramente com a resina nãosulfonada. Os resultados são reportados em termos de concentração do contaminante na água antes e após tratamento. A diferença entre essas concentrações denota o quanto ficou retido na coluna. A expressão "eficiência de remoção" diz respeito à quantidade de contaminante que ficou retido na coluna em relação à quantidade presente originalmente na água, expressa em porcentagem.

\section{Resultados e Discussão}

\section{Caracterização dos copolímeros}

As resinas obtidas foram submetidas à separação granulométrica. A faixa de tamanho de maior rendimento foi de 150 - $88 \mu \mathrm{m}$. Este material foi selecionado para as reações de sulfonação e para os ensaios de avaliação de desempenho no tratamento de água.

A Tabela 3 apresenta os resultados de caracterização obtidos para as resinas não modificadas (MMA-DVB e Sty-DVB) e para a resina sulfonada (S-Sty-DVB).

Comparando-se as resinas Sty-DVB e S-Sty-DVB, observa-se uma expressiva redução da área superficial e, consequentemente, o aumento do diâmetro médio dos poros, que podem ser atribuídos às drásticas condições as quais a resina foi submetida durante a reação de sulfonação. É possível notar também um aumento da densidade aparente do material em razão da substituição dos hidrogênios do anel aromático pelos grupos ácido sulfônico $\left(-\mathrm{SO}_{3} \mathrm{H}\right)$. O aumento do inchamento percentual pode ser explicado pelo mesmo motivo, uma vez que os grupos sulfônicos conferem maior polaridade à resina, de forma que o solvente empregado nos testes de inchamento (água e etanol (1:1)) possui maior afinidade pela resina sulfonada (S-Sty-DVB) do que pela resina não sulfonada (Sty-DVB).

O espectro de infravermelho da resina MMA-DVB apresenta uma banda em $2945 \mathrm{~cm}^{-1}$, atribuída à vibração axial do grupo $\mathrm{C}-\mathrm{H}$ tanto para o anel aromático, quanto para os grupos metila do metacrilato, e metileno. Em $1726 \mathrm{~cm}^{-1}$ observa-se uma banda característica de carbonila. Em 1446 e $1435 \mathrm{~cm}^{-1}$, verificam-se duas bandas de intensidade média que podem ser atribuídas tanto ao estiramento das ligações $\mathrm{C}=\mathrm{C}$, referentes ao anel aromático, quanto à deformação assimétrica $\mathrm{C}-\mathrm{H}$, dos

Tabela 2. Recheios das colunas empregadas no tratamento das águas.

\begin{tabular}{|c|c|c|}
\hline & Água contendo óleo & Água contendo anilina \\
\hline \multirow[t]{6}{*}{ Tipo de recheio de cada coluna } & $100 \%$ da resina Sty-DVB & $100 \%$ da resina Sty-DVB \\
\hline & $100 \%$ da resina S-Sty-DVB & $100 \%$ da resina S-Sty-DVB \\
\hline & $50 \%$ da resina Sty-DVB & - \\
\hline & $50 \%$ da resina S-Sty-DVB & \\
\hline & $50 \%$ da resina MMA-DVB & - \\
\hline & $50 \%$ da resina S-Sty-DVB & \\
\hline
\end{tabular}


Tabela 3. Caracterização das resinas não-modificadas e modificada.

\begin{tabular}{lccccc}
\hline \multicolumn{1}{c}{ Resina } & $\begin{array}{c}\mathbf{d}_{\text {ap }} \\
\left(\mathbf{g} / \mathbf{c m}^{\mathbf{3}}\right)\end{array}$ & $\begin{array}{c}\mathbf{A} \\
\left(\mathbf{m}^{2} \mathbf{g}\right)\end{array}$ & $\begin{array}{c}\varnothing \\
(\AA)\end{array}$ & $\begin{array}{c}\mathbf{I} \\
(\boldsymbol{\%})\end{array}$ & $\begin{array}{c}\text { CTC } \\
(\mathbf{m m o l} / \mathbf{g})\end{array}$ \\
\hline MMA-DVB & 0,33 & 25,18 & 142,70 & 11,5 & - \\
Sty-DVB & 0,39 & 101,28 & 178,30 & 13,3 & - \\
S-Sty-DVB & 0,59 & 46,94 & 231,92 & 33,3 & 6,36 \\
\hline
\end{tabular}

$\mathrm{d}_{\mathrm{ap}}=$ densidade aparente; $\mathrm{A}=$ área superficial; $\mathrm{V}_{\mathrm{p}}=$ volume de poros; $\mathrm{I}=$ inchamento percentual; $\varnothing=$ diâmetro de poros; CTC $=$ capacidade de troca catiônica.

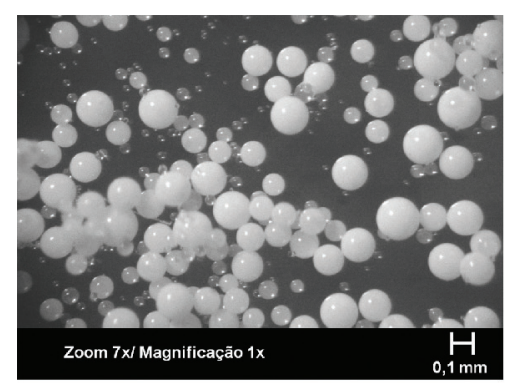

(a)

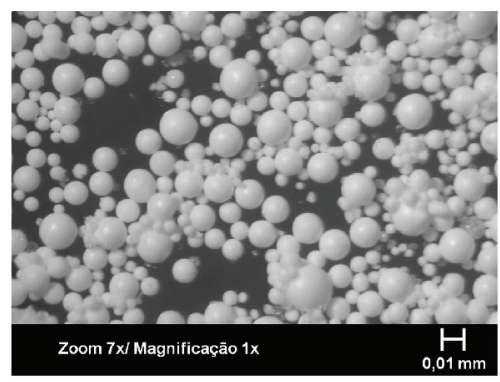

(b)

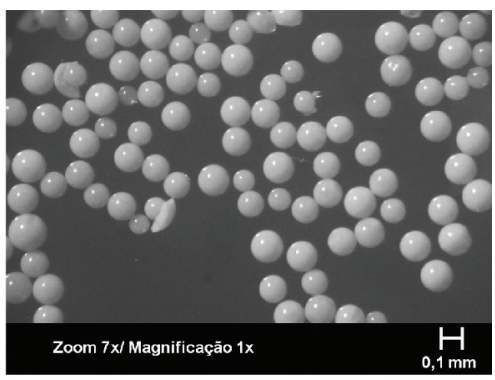

(c)

Figura 1. Micrografias de microscopia óptica para as resinas: (a) MMA-DVB, (b) Sty-DVB e (c) S-Sty-DVB.

grupos metila, do éster. As bandas em 1192 e $1139 \mathrm{~cm}^{-1}$ podem ser atribuídas ao estiramento $\mathrm{C}-\mathrm{O}$ do éster. Finalmente, em $707 \mathrm{~cm}^{-1}$ é observada uma banda referente à vibração $\mathrm{C}-\mathrm{H}$ angular fora do plano, correspondente a anel aromático dissubstituído.

Os espectros de infravermelho da resina Sty-DVB antes e após a sulfonação apresentam as mesmas bandas já descritas na literatura ${ }^{[18,21]}$. Para a resina não sulfonada observam-se bandas na região entre 3057 e $2848 \mathrm{~cm}^{-1}$ correspondentes à vibração axial $\mathrm{C}-\mathrm{H}$ dos grupos metilênicos e aromáticos. As bandas em 1600, 1492 e $1452 \mathrm{~cm}^{-1}$ podem ser atribuídas à deformação axial $\mathrm{C}=\mathrm{C}$ no anel, enquanto as bandas em 756 e $698 \mathrm{~cm}^{-1}$ podem ser atribuídas à deformação fora do plano dos grupos $\mathrm{C}-\mathrm{H}$ correspondentes, respectivamente, ao anel aromático monossubstituído e dissubstituído.

Já no espectro da resina sulfonada, observa-se, além das bandas assinaladas na amostra não sulfonada, uma banda larga em $3394 \mathrm{~cm}^{-1}$, atribuída à deformação axial da ligação O-H dos grupos sulfônicos. As bandas em 1199, 1134 e $1122 \mathrm{~cm}^{-1}$ correspondem à deformação axial simétrica do grupo $\mathrm{S}(=\mathrm{O})_{2}$, enquanto que as bandas em 1031 e 1004 cm$^{-1}$, correspondem à deformação axial assimétrica deste grupo.

A análise de microscopia óptica foi realizada com o objetivo de visualizar alguns aspectos morfológicos, como forma esférica das pérolas, integridade e presença de poros. Pérolas com formas heterogêneas e/ou fraturadas não poderiam ser utilizadas nos testes de eluição, pois se tornariam mais suscetíveis à ruptura quando submetidas à pressão. A Figura 1 apresenta as micrografias ópticas dos materiais sintetizados. O aspecto leitoso exibido pelas pérolas revela, como esperado, a existência de poros na resina. A morfologia esférica e íntegra torna os materiais aptos a serem empacotados em colunas de aço e submetidos às pressões aplicadas durante o processo de tratamento de água.

\section{Avaliação das resinas no tratamento de água}

Os resultados de avaliação de eficiência serão apresentados em função do tipo de coluna utilizada. Estudos anteriores ${ }^{[10]}$ mostraram que a variação da razão altura/diâmetro na faixa de 4 a 25 não altera significativamente os resultados de desempenho da coluna no tratamento de água contaminada com petróleo. Deste modo, a fim de acelerar a obtenção dos resultados experimentais, foi selecionada para este trabalho, um coluna de apenas $30,18 \mathrm{~mm}$ de altura e com 7, $38 \mathrm{~mm}$ de diâmetro, correspondendo a uma razão altura/diâmetro de 4,09 .

\section{Coluna contendo 100\% da resina Sty-DVB}

O gráfico de concentração versus volume eluído mostrado na Figura 2 apresenta o perfil de concentração da água oleosa antes e após tratamento. Como esperado, é possível observar uma eficiência de $100 \%$ de remoção ao longo dos primeiros $20 \mathrm{~L}$ de água oleosa eluída, correspondentes à aproximadamente 20 mil vezes o volume do leito, atribuída à evidente afinidade entre a resina e o óleo.

Ao contrário do resultado obtido no tratamento da água oleosa, não foi verificada nenhuma eficiência de remoção de anilina da água. O perfil de concentração, mostrado na Figura 3, sugere que a saturação da resina tenha se dado nos primeiros $100 \mathrm{~mL}$ de água eluída.

Esse resultado pode ser explicado pela baixa afinidade entre a resina, de caráter apolar composta por anéis aromáticos, e a anilina, de caráter polar conferido pelo grupamento amina. Sendo assim, os testes foram repetidos, porém, utilizando a resina sulfonada para que fosse estabelecida uma comparação entre os desempenhos exibidos pelas resinas.

\section{Coluna contendo 100\% da resina S-Sty-DVB}

O emprego da resina sulfonada, para o tratamento da água contendo anilina apresentou um aumento 


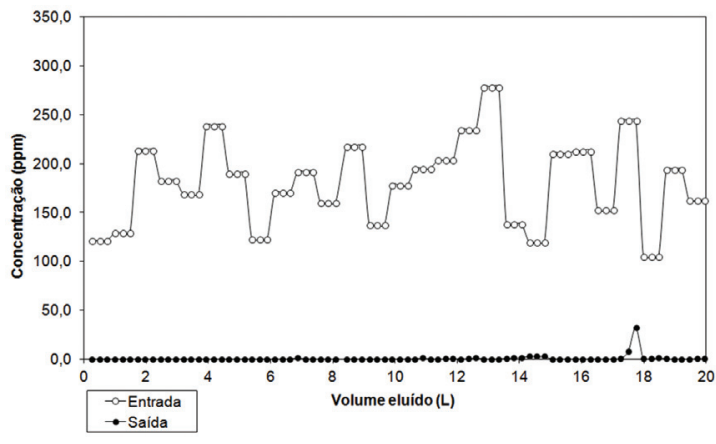

Figura 2. Perfil de eluição da água oleosa com o emprego da resina não modificada (Sty-DVB).

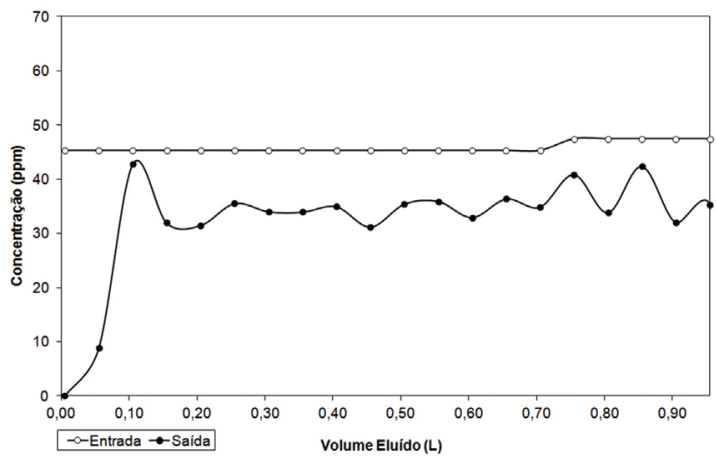

Figura 3. Perfil de eluição da água contaminada com anilina com o emprego da resina não modificada (Sty-DVB).

expressivo na eficiência de remoção, conforme mostrado na Figura 4. Observa-se $100 \%$ de remoção de anilina até aproximadamente $2 \mathrm{~L}$ de água eluída, quando então inicia-se um aumento gradual de anilina na água após o tratamento.

Essa elevada eficiência inicial pode ser atribuída à ocorrência de uma reação ácido-base entre os grupos ácido sulfônico, presentes na resina, e a anilina. Essa reação, por sua vez, promove outra modificação química na resina aumentando sua hidrofobicidade (Figura 5): a resina sulfonada apresenta uma elevada polaridade, que é reduzida pela incorporação de moléculas de anilina, tornando o caráter da resina menos polar.

A observação do aumento gradual da concentração de anilina na água eluída corrobora a hipótese de formação do sal de anilínio (espécie c da Figura 5), o qual estaria interagindo com outras moléculas de anilina. Caso esse fenômeno não ocorresse, imediatamente após a extinção dos sítios ácidos, seria observado um comportamento semelhante ao exibido pela resina não sulfonada: aumento abrupto da concentração de anilina em água na saída da coluna.

O espectro de infravermelho da resina após a eluição da água contaminada com anilina, mostrado na Figura 6, permite observar a formação do sal de anilínio, confirmando a reação ácido-base proposta. Em $2914 \mathrm{~cm}^{-1}$ tem-se uma banda alargada, atribuída às deformações axiais simétrica e assimétrica do grupamento $\mathrm{NH}_{3}{ }^{+} \mathrm{e} \mathrm{em}$ 1598 e $1494 \mathrm{~cm}^{-1}$, atribuídas às deformações angulares da ligação $\mathrm{N}-\mathrm{H}$, assimétrica e simétrica, respectivamente.

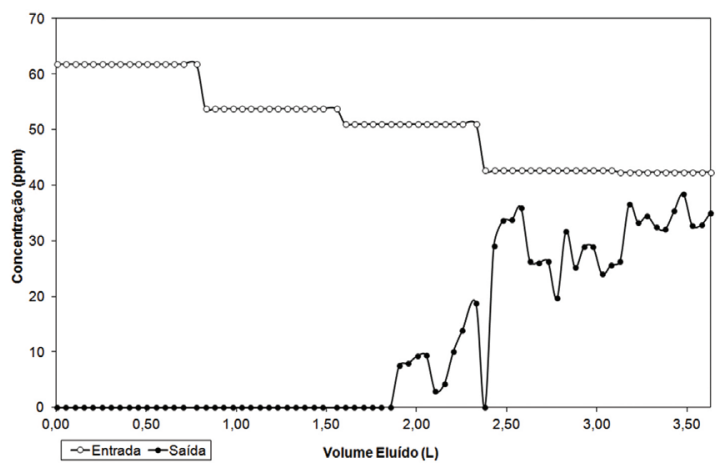

Figura 4. Perfil de eluição da água contaminada com anilina com o emprego da resina sulfonada (S-Sty-DVB).

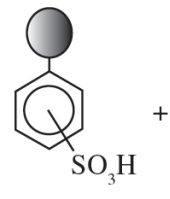

(a)

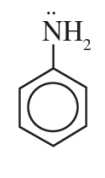

(b)

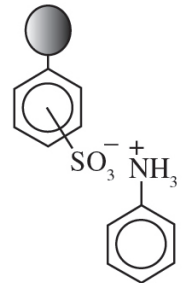

(c)
Figura 5. Reação ácido-base entre anilina e a resina sulfonada.

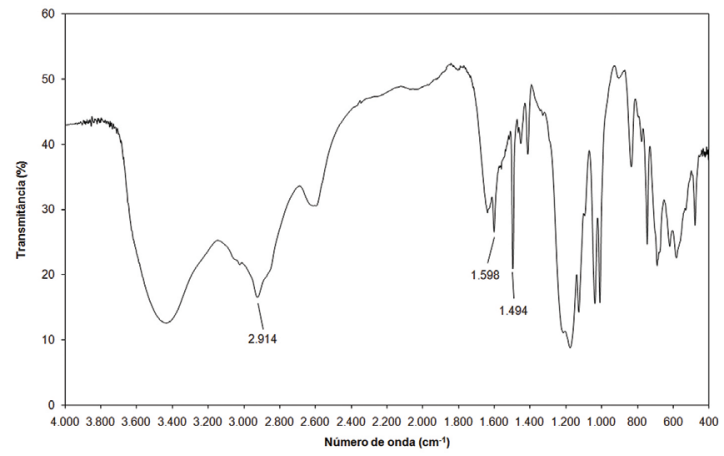

Figura 6. Espectro de infravermelho da resina sulfonada (S-StyDVB) após a eluição da água contendo anilina.

Embora a resina tenha apresentado um aumento na eficiência de remoção de anilina, esta apresentou uma redução do desempenho para a remoção de óleo, conforme ilustra a Figura 7. Além dos resultados para a remoção de óleo, o gráfico mostra o comportamento do $\mathrm{pH}$ ao longo do processo de tratamento, o qual fornece informação sobre o fenômeno de troca iônica.

A redução da eficiência de $100 \%$ da resina não sulfonada para $91 \%$ da resina sulfonada pode ser atribuída à redução da afinidade resina-óleo decorrente da presença dos grupos ácido sulfônico, de maior polaridade. No entanto, a resina sulfonada, mesmo não removendo o óleo como a resina não sulfonada, é capaz de realizar troca iônica, possibilitando a remoção dos íons sódio e cálcio presentes na água salina utilizada no preparo da água oleosa.

O fenômeno de troca iônica pode ser acompanhado através do comportamento do $\mathrm{pH}$ ao longo do processo 


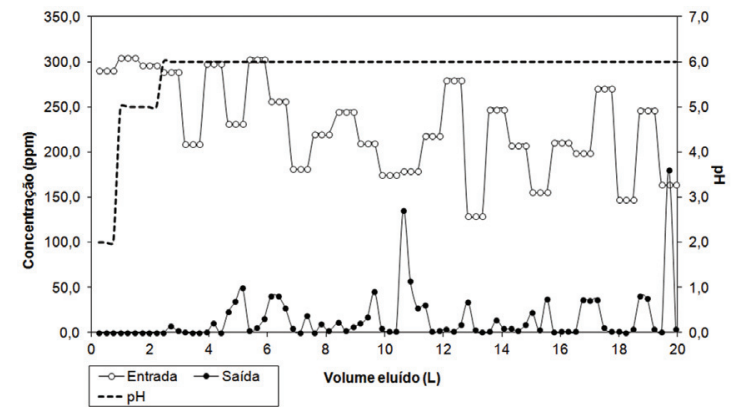

Figura 7. Perfil de eluição da água oleosa através da resina sulfonada (S-Sty-DVB).

de eluição, representado pela linha pontilhada no gráfico da Figura 7. Pode-se observar que o equilíbrio da troca iônica foi atingido após o terceiro litro de água eluído, correspondente a três mil vezes o volume de leito, onde o valor do $\mathrm{pH}$ mostrou-se constante em 6, o mesmo $\mathrm{pH}$ da água salina utilizada no preparo da água oleosa.

Coluna com recheio misto contendo as resinas Sty-DVB e S-Sty-DVB

Segundo é descrito na literatura, a presença de óleo interfere negativamente no processo de troca iônica pela formação de um filme bloqueando os sítios de troca ${ }^{[22]}$. Sendo assim, uma coluna foi preenchida em série com as resinas Sty-DVB (não sulfonada) e S-Sty-DVB (sulfonada), na proporção 50/50, de modo que a água oleosa entrasse em contato primeiramente com a resina não sulfonada com o objetivo de remover uma grande quantidade de óleo para que, dessa forma, a interferência do óleo fosse mínima quando a água atingisse a porção da coluna que continha a resina sulfonada.

A Figura 8 mostra uma eficiência de remoção de óleo de mais de $99 \%$ durante todo o processo. A curva de $\mathrm{pH}$ versus volume eluído mostra uma extinção dos sítios de troca no segundo litro. Esse volume quando comparado ao volume em que foi alcançada a saturação dos sítios ácidos da resina sulfonada, de 3 litros, evidencia que para a metade da quantidade de resina a eficiência do fenômeno de troca foi semelhante.

Coluna com recheio misto contendo as resinas MMA-DVB e S-Sty-DVB

Visando utilizar um material adsorvente economicamente mais favorável, a resina à base de estireno foi substituída por outra à base de metacrilato de metila. Novamente foi utilizada uma coluna com recheio misto contendo as resinas MMA-DVB e S-Sty-DVB com a mesma disposição em série da outra coluna mista, ou seja, de modo que a água oleosa entrasse em contato primeiramente com a resina MMA-DVB e, em seguida, com a resina S-Sty-DVB.

O perfil de eluição apresentado na Figura 9 mostra um resultado bastante semelhante ao obtido com a coluna recheada com as resinas Sty-DVB e S-Sty-DVB, tanto no que se refere à adsorção de óleo quanto ao comportamento da troca iônica, indicando que a substituição do estireno pelo metacrilato de metila na resina promove uma redução no custo da resina sem afetar de maneira considerável a eficiência de remoção do óleo.

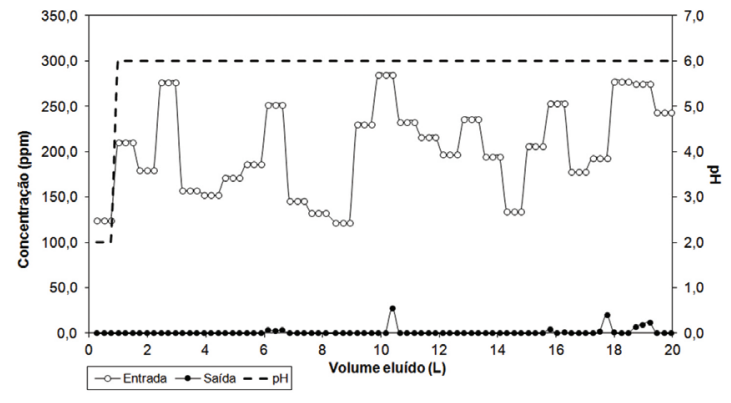

Figura 8. Perfil de eluição da água oleosa na coluna contendo as resinas Sty-DVB e S-Sty-DVB.

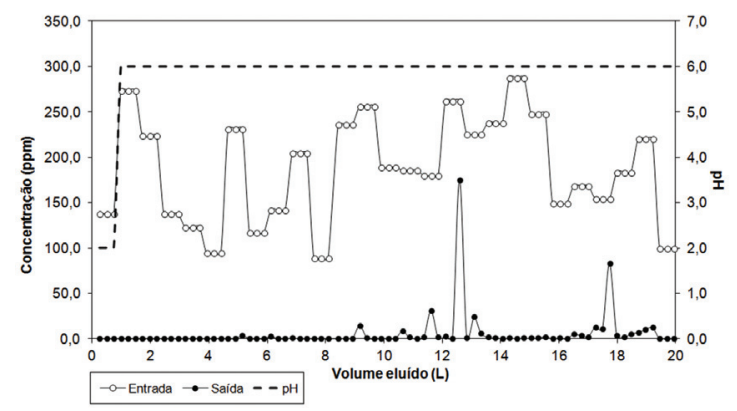

Figura 9. Perfil de eluição da água oleosa na coluna contendo as resinas MMA-DVB e S-Sty-DVB.

\section{Conclusões}

A resina não modificada de estireno-divinilbenzeno (Sty-DVB) apresentou um desempenho de remoção de óleo superior ao exibido pela resina de estirenodivinilbenzeno sulfonada (S-Sty-DVB). Em contrapartida, a resina sulfonada (S-Sty-DVB), mesmo apresentando uma ligeira queda na capacidade de remoção de óleo, mostrou um caráter anfifílico, sendo capaz de remover tanto o óleo quando os cátions cálcio e sódio presentes na água oleosa. No entanto, a troca iônica, responsável pela remoção desses cátions e outros contaminantes polares é prejudicada quando o meio possui óleo.

Em relação à remoção de anilina, a resina sulfonada foi a que apresentou bom desempenho. A interação das moléculas de anilina com o grupo sulfônico da resina ocorre através de uma reação ácido-base com formação do sal de anilínio, o que foi constatado através do perfil de concentração da água tratada e do espectro de infravermelho da resina após sua utilização.

Visando minimizar os efeitos adversos que ocorrem na resina sulfonada, o emprego de sistemas mistos tornase uma alternativa altamente recomendável na remoção de uma vasta gama de contaminantes presentes na água produzida pela indústria do petróleo, possibilitando seu descarte ou o reuso sem causar impactos significativos ao meio ambiente.

\section{Agradecimentos}

Os autores agradecem a Petrobras, CAPES, CNPq e FAPERJ. 


\section{Referências Bibliográficas}

1. McCormack, P.; Jones, P.; Hetheridge, M. J. \& Rowland, S. J. - Wat. Res., 35, p.3567 (2001). http://dx.doi.org/10.1016/ S0043-1354(01)00070-7

2. Stephenson, M. T. - J. Petr. Tech., 44, p.548 (1992).

3. Oliveira, R. C. G. \& Oliveira, M. C. K. - Bol. Téc. Petrobras, 43, p.129 (2000).

4. Queirós, Y. G. C.; Clarisse, M. D.; Oliveira, R. S.; Reis, B. D.; Lucas, E. F. \& Louvisse, A. M. T. - Polímeros, 16, p.224 (2006).

5. Conselho Nacional do Meio Ambiente - CONAMA - "Livro de Resoluções do CONAMA", Ministério do Meio Ambiente, Brasília (2007).

6. Jiang, H.; Fang, Y.; Fu, Y. \& Guo, Q. - J. Haz. Mat., B101, p.179 (2003). http://dx.doi.org/10.1016/S03043894(03)00176-6

7. Wandera, D.; Wickramasinghe, S. R. \& Husson, S. M. - J. Memb. Sci., 373, p.178 (2011). http://dx.doi.org/10.1016/j. memsci.2011.03.010

8. Wu, C.; Li, A.; Li, E.; Zhang, L.; Wang, H.; Qi, X. \& Zhang, Q. - Desalination, 225, p.312 (2008). http://dx.doi. org/10.1016/j.desal.2007.07.012

9. Al-Jeshi, S. \& Neville, A. - Desalination, 228, p.287 (2008). http://dx.doi.org/10.1016/j.desal.2007.11.009

10. Queirós, Y. G. C. - "Avaliação de resinas poliméricas no processo de purificação de água contaminada com componentes aromáticos", Tese de Doutorado, Universidade Federal do Rio de Janeiro, Brasil (2006).

11. Louvisse, A. M. T.; Lucas, E. F.; Barbosa, L. C. F.; Clarisse, M. D. \& Queiros, Y. G. C. - "Método de remoção de óleo e graxa em água por adsorção em resina polimérica", PI 0803656-0, Petrobras (2008).
12. Clarisse, M.; Queirós, Y.; Barbosa, C.; Barbosa L. \& Lucas, E. - Chem. Chem. Technol., 6, p.1 (2012).

13. Silva, C. M. F; Barros, C. C.; Queirós, Y. G. C.; Marques, L. R. S.; Louvisse, A. M. T. \& Lucas, E. F. - Chem. Chem. Technol. In press.

14. Ergenekon, P.; Gürbulak, E. \& Keskinler, B. - Chem. Eng. Proces., 50, p.16 (2011). http://dx.doi.org/10.1016/j. cep.2010.10.009

15. Abrams, I. M. \& Millar, J. R. - React. \& Funct. Pol., 35, p.7 (1997). http://dx.doi.org/10.1016/S1381-5148(97)00058-8

16. Rezende, S. M.; Soares, B. G.; Coutinho, F. M. B.; Reis, S. C. M.; Reid, M. G.; Lachter, E. R. \& Nascimento, R. S. V. - Polímeros, 15, p.186 (2005).

17. Coutinho, F. M. B.; Cunha, L. \& Gomes, A. S. - Polímeros, 14, p.31 (2004).

18. Coutinho, F. M. B. \& Rezende, S. M. - Polímeros, 11, p.222 (2001). http://dx.doi.org/10.1590/S010414282001000400012

19. Lode, F.; Freitas, S.; Mazzotti, M. \& Morbidelli, M. - Ind. Eng. Chem. Res, 43, p.2658 (2004). http://dx.doi. org/10.1021/ie030664s

20. Ahmed, M.; Malik, M. A.; Pervez, S. \& Raffiq, M. - Eur. Pol. Journal, 40, p.1609 (2004). http://dx.doi.org/10.1016/j. eurpolymj.2004.04.013

21. Oliveira, A. J. B.; Aguiar, A. P.; Aguiar, M. R. M. P. \& Santa Maria, L. C. - Mat. Letters, 59, p.1089 (2005).

22. Meyers, P. S. - "Cleaning of Oil Fouled Softener Resins", in: 55th Annual International Water Conference, p.51, Pittsburgh - Pensylvania, out-nov (1990).

Enviado: $16 / 04 / 12$ Reenviado: $23 / 07 / 12$ Aceito: $02 / 08 / 12$ 